\title{
Instruction development that incorporates active learning to nurture 21st century skills
}

\author{
Yukiko Ibuki \\ Kyoto Gakuen Junior and Senior High School \\ 8 Teranonaka, Hanazono, Ukyo-ku, Kyoto, Japan 616-8036 \\ Japan \\ ibuki@kyotogakuen.ed.jp
}

\begin{abstract}
Introduction
The exploratory process is described in "The Period of Integrated Study: An Exposition of Educational Guidelines" as a repetition of four steps: setting a theme, gathering information, analysis, and expression. The Active Learning framework seeks to further refine this process by emphasizing interaction and reflection wherever it is appropriate in the educational context.

In this study, in addition to maintaining the previous emphasis on cooperation and dialogue with other disciplines, we developed and implemented a teaching program that encourages the communication/presentation of information by gathering various resources, processing it intellectually, and then outputting the results as a part of a continuous educational process.
\end{abstract}

\section{Research objective}

Objective of this research is to nurture media literacy and critical thinking by conducting Cross Curriculum active learning lessons with English language teacher.

\section{Research Methods}

"The Tale of Genji" was used as a theme for the class. The text was compared with English translations to stimulate thinking on world views. Many group discussions on how characters and characteristic Japanese sensitivities should be translated into English were included, and explanations were given while via reference to library materials. The NIE technique was used to incorporate what was learned. By using the school library not only as a research tool but also as a way of stressing the importance of active experience, students were able to realize their "own respective selves." In order to have students experience the continuing integral importance of culture in dynastic Kyoto, they conducted interviews regarding the Aoi-matsuri Festival. Research perspectives were collected as articles, columns and advertisements on a single sheet of newspaper. The Moodle 
system from High School located in California was used to distribute the newspaper and conduct online collaboration.

\section{Research Results}

Distributing a "rubric" as an evaluation method, 5 abilities were jointly assessed: communication skills, information analysis, critical thinking, English proficiency and teamwork. Through the rubric, by reading while comparing with the other group's newspaper, different value judgments emerged in connection with article information uptake and a new perspective was discovered. In addition, by considering classical literature through the filter of English, it was possible to think about the sense of the uniquely Japanese from a perspective different from that of the usual class.

\section{Conclusion}

Incorporation of active learning cultivated students' ability to conduct value judgments and read large quantities of opinions from multiple perspectives, organizing one's opinions while also cultivating the opinion-generating capacity and critical thinking ability of oneself and one's group. Through newspaper construction, students were able to tangibly feel group value judgments, achieving mutual understanding while also reaching class goals - they were able to realize the significance of the effort.

One future challenge is that American high schools were not able to reach a level of active opinion exchange. In order to overcome students' differing regional cultures and learning histories, one potential solution would be to use Skype or education social media in order to have them conduct $Q \& A$ sessions and deepen each other's understandings.

Keywords: active learning, Newspaper in Education, media literacy, 21st century skills, Cross Curriculum

\section{Biographical note}

Yukiko Ibuki has worked as Academic Affairs Librarian Teacher at the Kyoto Gakuen Junior and Senior High School since 2006. My main research topic is the investigation of teaching methods for media literacy using "Newspaper in Education" (NIE). Another is the development of Project-Based Learning program with the aim of nurturing 21 st century skills such as critical thinking and communication skill. This is achieved by cooperating with the teachers of several subjects; integrating active learning, where students learn both subjectively and cooperatively; and making use of books, newspapers, and databases in the school library. Additionally, I'm 
vice president of the Kyoto Prefecture School Library Association, a member of the Research Committee of the Japan Society for Studies in "Newspaper in Education" and NIE advisor. 